\title{
PLANNING ACTIONS IN THE EVENT OF AN EPIDEMIC OF INFECTIOUS DISEASES
}

\author{
Anna ŚWIĄTECKA' ${ }^{1}$, Wojciech DĘBIŃSKI ${ }^{2}$ \\ ${ }^{1}$ Banfield Pet Hospital, Washington, D.C., USA \\ ${ }^{2}$ Military Institute of Aviation Medicine, Aeronautical and Occupational Medicine Certification Center, \\ Warsaw, Poland
}

Source of support: Own sources

Author's address: A. Świątecka, Banfield Pet Hospital, Washington D.C., USA, e-mail: a.swiatecka@gmail.com

Introduction: Ease of travel, especially by air, increases the risk of spreading dangerous infectious diseases not only within countries but also between continents. The authors analyze the actions taken during the EBOLA epidemic in 2014-2015 against the background of the procedures implemented during the influenza pandemic and SARS epidemic.

Problems: The main problem before and during an epidemic or pandemic of infectious diseases is the preparation of appropriate tools to be used from the first moments of the threat. Close cooperation between and coordination of all services involved in the decommissioning of epidemic outbreaks is becoming essential.

Conclusion: It is necessary to develop appropriate plans concerning unified risk management procedures. They should take into account not only the activities of medical services, but also representatives of other areas (including airline workers, critical infrastructure systems, the media, as well as representatives of the political level).

Keywords: epidemic, infectious diseases, EBOLA, SARS, influenza pandemic, air transport 


\section{INTRODUCTION}

The epidemic of the EBOLA viral disease, which occurred in 2014-2015, showed that infectious diseases cannot be treated solely in the context of a historical or exotic phenomena. Both previously known infectious diseases and the so-called emerging diseases are the cause not only of human illness and death, but also of huge economic and political losses.

The constant accompanying development of civilization is simultaneously a source of new tools useful for responding, as well as an element conducive to a faster spread of infectious diseases even from the most distant regions of the world. Experts stress that the time needed to bridge the gap between the two most remote places on earth is shorter than the incubation period for infectious diseases that have so far been identified in humans. As a result, we may be exposed to new threats every day, the effects of which are difficult to predict [2].

The current political situation poses another threat as well. The increased threat of terrorist attacks worldwide, including in Europe, makes bioterrorism a current phenomenon [2].

Therefore, with progress and political changes as well as increasing public health threats, our approach to action planning in the event of an epidemic of infectious diseases must be modified and the treatment of infectious diseases as an exotic problem that does not concern us must stop. These changes were partly introduced already during the preparations for the influenza pandemic, carried out before 2009, however, when analyzing the later actions, e.g. during the EBOLA epidemic, it is clear that unfortunately they have not become a standard in responding to other infectious diseases [16].

Preparations for most crisis situations are carried out on a multidirectional basis, at all level of responses, but very rarely as systemic, longterm strategies $[16,17]$. According to the authors, the priorities in the area of preparation are most often imposed by the existing or upcoming crisis situation and are not aimed at improving the entire response system in their nature, but only at resolving an existing or upcoming threat. Preparations are usually conducted on a "crisis to crisis" basis, and a multitude of teams, plans, procedures and tools are not always conducive to an optimal exchange of information or a more comprehensive approach to the issue, and often even lead to chaos and decisions that are not very rational. Very often, the need for the universal nature of adopted solutions that could be included in more practical, universal strategies is not taken into account.
Lack of such solutions results in the fact that the effectiveness and efficiency of actions taken at the moment of occurrence of a specific threat is often inadequate to the needs and generates both financial and time losses, which, in the opinion of the authors, is of great importance in the case of continuous shortages of both time and money in the entire crisis response system.

Of course, key aspects in biological emergency preparations are those arising from the nature of the biological agents, the characteristics of the exposed population, but also from the risk management measures available. Unfortunately, at the present we must also accept the fact that the political and economic situation has a huge impact on the action planning possibilities. The negative influence of these factors needs to be analyzed very carefully in order to improve the efficiency of the preparations. As previous epidemics have shown, political decisions are often the cause of difficulties in the implementation of plans and procedures, resulting in a loss of public trust in the actions taken by medical experts.

In any crisis situation, including an epidemic of an infectious disease, the media play an important role. As experience from e.g. the epidemic of the viral disease Ebola shows, the role of both traditional media (radio, television, press) and e.g. digital media and information tools available in cyberspace is huge. Their inclusion in preparation and response plans is a necessity which requires long-term action. According to the authors, it is necessary to standardize procedures and to cooperate closely with the WHO in this respect.

Taking the above into account, the aim of the study was to:

1. Demonstrate the state of preparations for threats related to the spread of dangerous infectious diseases.

2. Discussion of the problems identified by international expert groups, in the context of local and national preparations.

3. Identification of proposed systemic solutions necessary to continue preparations.

\section{THE EBOLA VIRAL DISEASE EPIDEMIC}

The Ebola viral disease virus was first identified in the 1970s Since then, until 2013/2014, all outbreaks of this disease had a similar course [13]. The disease was mainly found in Central Africa, with several to several hundred deaths usually occurring in the identified outbreaks. At the same time, they were limited in time, place and population. 
Between the identification of Ebola hemorrhagic fever and 2014, a total of approximately 1,500-1,600 deaths (fewer than 40 deaths per year since the virus was discovered) were reported. Despite the use of the Ebola model in many exercise, plan and procedure scenarios [21,22], in America, Asia and Europe it still was an example of an exotic or bioterroristic disease.

The situation changed at the turn of 2013 and 2014, when the cases were confirmed for the first time in West Africa $[3,4,13]$. The scale of the epidemic, the place case of illness and death occurrence, surprised everyone. Between 2014 and 2015 alone, the disease caused 27,000 cases, including 11,000 deaths. It was the longest lasting epidemic of this disease $[7,20]$. Although the first cases occurred in South Guinea in December 2013, the epidemic remained unrecognized until March 2014, allowing the virus to spread to Sierra Leone and Liberia (via land borders) and by air to Nigeria, the most populated country in Africa. Despite alarming appeals from non-governmental organizations present in the region, including Doctors Without Borders, about the growing scale of the threat and the need to take urgent action, it was not until August 2014 when the World Health Organization (WHO) has recognized this epidemic as a Public Health Emergency of International Concern (PHEIC) in accordance with the International Health Regulations 2005 (IHR 2005).

During the course of the epidemic, the virus spread to other African countries (Senegal and Mali). In addition, Ebola infections have occurred in the UK, Italy, Spain and the US, countries providing help to infected people. In order to receive appropriate treatment, those affected were transported to their countries of origin. Naturally, imported cases of the disease occurred in the USA, Italy, Great Britain, and virus transmission occurred in Spain and the USA [20].

Because the course of epidemic was so rapid and differed from any previous one, many experts asked themselves what caused such large differences in its course, in comparison to previous epidemics of this disease $[3,4,7]$.

Initially, it seemed that the virus that had appeared in the region quickly mutated and gained the possibility to spread more easily and greater virulence. The possibility of changes in the genome caused by late diagnosis of the disease and long-term circulation of the virus among the population was also considered $[3,15,20]$.

Later genetic analyses did not confirm these hypotheses. The virus circulating in West Africa was very similar to the one found in Central Africa. The differences in the genome were so small that they should not cause differences in the spread of the disease. Also, the pathogenesis of the disease did not indicate that the severity of the outbreak and the characteristics of the epidemic were caused by changes in the virus characteristics [16].

In view of the above, a number of questions arose:

1. What was the cause of such a large scale epidemic?

2. What factors prevented us from being able to control it quickly?

3. Why did the tools developed for responding in case of an infectious disease not work, or proven to be insufficient?

4. Did the 2005 IHR, as the legal basis for preparation and response, trained during the influenza $A(H 1 N 1) p d m 09$ pandemic among others, prove ineffective in the case of other infectious diseases? [11.12]

To answer these questions, many international expert teams have taken action to carefully analyze the situation and the actions taken in order to identify both the strengths and weaknesses of the system and to implement corrective actions [16].

Also from Poland's perspective, it became necessary to carefully analyze the actions taken during the Ebola epidemic at each level of response, taking into account the specificity of countries particularly affected, referring them to the actions taken during previous epidemics of infectious diseases and developing on this basis appropriate preparation plans for our country.

The analysis cannot, of course, ignore the geopolitical situation of West African countries, since one of the main and quite obvious reasons for the failure of the response at national level in the region was the result of a long lasting civil war as well as the political and economic weakness of both Liberia and Sierra Leone. During the war, existing infrastructure, including medical infrastructure, was significantly destroyed. The lack of a coherent system of surveillance over infectious diseases caused delays in reporting in practice and thus prevented efficient implementation of early actions adequate to the scale of the threat. Ubiquitous corruption and a total lack of public trust in the governments of these countries proved to be an important factor. The authorities did not know how to react, primarily placing economic reasons above efficient and effective, and most importantly - quick response. Also, the great effects of delayed response to the threat were not foreseen [16]. It needs to be noted that a similar situation occurred during the SARS epidemic 
when a suspicion that China tried to "cover" the epidemic and did not report the cases to the WHO arose. This delayed the containment of the virus at the international level and caused considerable economic losses [11,12].

It is on the basis of this experience that the 2005 IHR imposed an duty to report information on risks on WHO Member States. According to the adopted assumptions, each country has 24 hours to report $[11,12]$. However, as the Ebola epidemic has shown, the possibilities for enforcing this duty remain very limited.

The social and economic situation of the countries affected by the Ebola virus has also had a huge impact on the shortage of medical staff. In Liberia alone, according to 2010 data, there were 51 doctors per 4 million people. At the same time, doctors or nurses from other countries often faced mistrust in many places they worked, especially when they appeared in strange and dangerously looking protective clothing. Often, medical staff dressed in such a way was a source of anxiety and sometimes even fear, which made it difficult for them to work with the local community.

Lack of previous experience, concerning the reaction during the viral disease Ebola was also not without significance. It was not present in the region before and, due to its non-specific symptoms, it took about three months to identify the real causes of the disease and death. In many places (according to local authorities of e.g. Liberia), Ebola has not been taken into account as a cause of illness for a long time and has not been registered in surveillance systems. The causes associated with the non-specific symptoms were often seen in other diseases, including malaria in these areas in particular.

The nonspecific course of the disease and the lack of appropriate infrastructure and equipment have also made it difficult to organize special isolation facilities for people infected with the Ebola virus, the so called Ebola Treatment Units - ETU. When the onset of symptoms of the disease occurred, the persons were directed to specially prepared rooms. Unfortunately, while waiting for laboratory tests, which lasted up to 2-3 days, the infected people stayed in one place with those that showed symptoms caused by other diseases. This posed a risk of further spread of the disease to people suffering from other conditions. There is no data available on the number of hospital-acquired infections that have occurred in connection with such management, but it can be assumed that such organization has not been conducive to building confidence in medical procedures and proceedings. Those sent to ETU often thought that they were being sentenced to death in isolation in these places. There were cases of people diagnosed with Ebola, who, not wanting to undergo treatment in an ETU, traveled many hours to other distant places to meet the family. This, of course, caused the spread of the disease and new outbreaks.

Insufficient security of medical staff during the course of the epidemic was a serious problem. The lack of appropriate protective suits, incompetent use of personal protective equipment caused the disease in the initial period of the epidemic to affect, to a large extent, the people who took care of the sick. This is why some doctors or nurses, fearing for the health of their own and that of their families, have considered refusing to help. Similar situations occurred during the yellow fever epidemic in the USA, SARS or the influenza pandemic [11]. The experience of doctors working in countries affected by dangerous infectious diseases has often shown how difficult were the choices they were forced to make.

It should be emphasized that working in protective suits, which provide the comfort of safety for medical personnel, requires appropriate training. In addition, this work is very physically demanding and therefore time-consuming. The number of people seeking help was enormous, which created discomfort for medical workers, including mental discomfort. The situation was improved by regular training sessions addressed to the staff going to the areas of disease occurrence which were conducted by CDC, WHO or the Doctors Without Borders organization, among others [10].

The traditions and beliefs of the local population concerning e.g. care for the sick persons and methods of burial, during which direct contact with corpses often took place also proved to be a big problem [1]. Therefore, as it was the case during previous Ebola epidemics, the virus spread most intensively among those who took care of the sick or took part in funeral ceremonies $[1,8,14]$.

The lack of an effective surveillance system, difficulties in reaching all the regions of the country where the disease occurred are other key problems which, unfortunately, have also had a huge negative impact on the epidemiological situation and the ability to react in other regions of the continent and even the world. It has been repeatedly emphasized that the existing possibilities for movement of people between villages and towns have led to the rapid spread of the virus from east 
to west and only being stopped when it reached the ocean, a natural barrier.

The problems described above resulted, inter alia, from the lack of precise action plans, also at national level, in particular with regard to the proper functioning of the crisis management system. The procedures adopted were so lacking that they could not cope with the rapidly deteriorating epidemiological situation. This caused great difficulties in utilizing the international aid that arrived to countries affected by the pandemic. The lack of an appropriate system and system management has shown that it is not enough to have the resources alone, when, for various reasons, it is not possible to provide them to those in need or to the medical staff involved in the decommissioning of the outbreaks. Even large financial outlays do not bring the expected results without the support of the entire system.

The actions taken during the course of the Ebola epidemic, as well as the influenza pandemic, have also shown how important it is to strike the right balance between limiting the spread of the disease and minimizing its negative effects. According to several experts $[16,17]$, many places neglected to act in the focal points, focusing entirely on the isolation of patients, and not on providing them with adequate medical assistance during the Ebola epidemic. Isolated people, who virtually were not granted proper medical care, did not want to submit themselves to restrictions and avoided services involved in extinguishing outbreaks of disease. Only when the population noticed that cured people were returning from the places of care of the sick it was seen as a positive turning point of the epidemic. This helped to improve cooperation between the local community and medical staff.

\section{ACTIONS OF THE AVIATION SECTOR DURING THE EBOLA VIRUS EPIDEMIC}

In addition to the problems in the functioning of the medical sector, the performance of other key elements of national response systems has also been the subject of a lot of controversy.

The functioning of airport services and airline representatives in the affected countries raised many doubts $[5,18]$. For example, out of 7 airlines using the Monrovia airport (Liberia), 5 have withdrawn and only 2 have remained. This significantly reduced the ability to deliver food, disinfectants and specialist equipment by air, and made it difficult to evacuate and turnover personnel.
Measures to reduce air communication have been taken despite clear WHO guidance on the lack of the need for travel restrictions. These decisions proved to be another negative factor influencing the correct response to the threat. For the citizens of the affected countries, this created a feeling of fear and complete isolation from the rest of the world. Air traffic restrictions have been imposed on Liberia, Sierra Leone and Guinea, yet no restrictions have been imposed on Nigeria, where, after all, cases have also been confirmed. This indicates that the WHO's recommendations are open to interpretation, which should not be the case in such an events.

Some countries, without consulting neighboring countries, decided to close their borders with the affected countries (e.g. Senegal closed its border with Guinea). These actions were not justified in any way and were undertaken contrary to the clear recommendations of the WHO.

A similar problem arose with the introduction of screening upon entering and leaving airports, seaports and at land crossings [18]. The WHO has developed clear guidelines in this respect, which state that it is appropriate to introduce 'exit-only' screening from countries with persistent virus transmission $[5,6,19]$. This was to prevent people showing symptoms of Ebola infection from being allowed to travel. In the document entitled "WHO Interim Guidance for Ebola Virus Disease: Exit Screening at Airports, Ports and Land Crossings (6 November 2014)", the WHO recommended the countries with reported Ebola virus transmission to carry out a screening on departure that included at least:

- filling in a relevant questionnaire,

- temperature measurement,

- in case a fever was indicated, an assessment of the health status and the degree of risk of the fever being caused by the infection with the Ebola virus.

In accordance with the recommendations, any person with symptoms corresponding to the Ebola viral disease and those having had contact with them should not travel $[5,19]$. The only exception in this case was transport connected with medical evacuation. The screening on departure was introduced by all affected countries where virus transmission was detected. In most cases, these activities were carried out with the support of the CDC. However, experience gained after only two months of applying that measure has shown that the real possibilities for detecting cases by that means are very limited. Among 36,000 people subjected to screening, only 77 were considered 
likely to be infected. After specialist examinations, none of the persons confirmed the preliminary diagnosis.

However, the WHO did not recommend the use of screening on entry into countries with persistent virus transmission. The ECDC also stressed in its recommendations that the introduction of entry screening can only be considered if there are doubts about the effectiveness of exit screening. At the same time, it was stressed that if countries decide to introduce such a measure, they should develop precise plans and procedures so that these actions would not lead to disruptions and delays in international traffic and transport. The WHO also recommended that not only the policy aspects should be taken into account in the decision-making process, but also the results of a thorough analysis of the benefits and losses of the decisions made. At the same time, it was recommended to consider the following:

- taking into account the lack of evidence that screening is effective in preventing or delaying the spread of infectious diseases,

- in the case of temperature measurement, using appropriate equipment and ensuring that it is used by trained personnel,

- taking into account the fact that the use of temperature measurement as one of the screening methods requires the development of methods for further treatment of patients with elevated temperature [19].

These recommendations were based on experience from previous epidemics (including SARS or pandemic influenza), which have shown that even among infected people, the possibility of detecting cases by means of this method is very low and the cost of introducing these measures is very high. At the same time, they require the use of appropriate equipment and properly trained staff. They can also have a very negative impact on the smooth flow of passenger transport and the functioning of airports. Despite these recommendations and the lessons learnt from previous epidemics, particularly SARS, some countries have decided to introduce this measure as well.

Transportation of samples of biological material for laboratory tests also turned out to be largely problematic. Despite quite clear guidelines on safe transport, many air carriers and delivery companies did not want to provide these services, justifying it with concern for the health and safety of staff.

The introduction of quarantine in both West African countries and the US has been similarly controversial. In the United States, the CDC decided that quarantine should be compulsory for all health professionals who have been caring of patients in affected countries. This was met with great opposition from many circles, including non-governmental organizations [16]. It was stressed that there was no scientific evidence of the spread of the virus from persons who did not show symptoms of the disease and that quarantine of returnees from affected areas, but not from symptomatic areas was therefore a superfluous measure, according to many experts.

Many problems with introducing quarantine have also been identified in West African countries. Food and basic disinfectants were often lacking in quarantine facilities. As mentioned above, this was due to the reduction of air transport, among others. Additionally, the fact that these places were protected by the army had a negative impact on the mental state of the people undergoing quarantine, which contributed to the rising of an atmosphere of fear and danger.

As in the case of the aforementioned examples, it is clear that the lessons learned from previous epidemics are not being used at all in the case of quarantine. Even a fairly thorough analysis of the costs and consequences of this measure did not provide a sufficient argument for decisionmakers.

All the above problems identified in the countries affected by the epidemic, both at the local and national level, were compounded by the fact that WHO did not respond quickly enough despite the threat signals from non-governmental organizations (including Doctors Without Borders) and, according to experts the organization's response was too late [16]. The response only came when the number of illnesses and deaths was enormous and when it was very difficult for the international community to respond. It is, of course, difficult to assess accurately how much earlier and more decisive action by the WHO would have helped to improve the situation, however it is very interesting to compare the situation again with the influenza $A(\mathrm{H} 1 \mathrm{~N} 1)$ pdm09 pandemic, where the WHO response was considered too early. It has been repeatedly stated that due to the mild course of the disease, the WHO response and recommendations should be milder. It is also difficult to assess whether this criticism has had any impact in delaying the decisions taken during the Ebola epidemic.

Particularly intense criticism concerning international action was voiced due to inadequate implementation and enforcement of the IHR 2005 $[11,12,16]$. This document, based on the SARS conclusions, among other things, sets out not only 
the rights and obligations of the various institutions involved in the response, but also, and this is important in terms of coordination, the range of key options that Member States should have at their disposal. They cover many aspects of preparation, from the preparation of staff and medical infrastructure through communication, surveillance of infectious diseases, involvement and preparation of all services involved in the elimination of the threat.

In order to improve preparedness and response capacity, the WHO has developed specific tools for capacity assessment. They allow to identify the strengths and weaknesses in the overall response system. Available data [11,12] show that currently only $20 \%$ of WHO Member States have reported preparedness in the context of having key response capabilities. However, it should be stressed that this result may be overestimated due to the fact that this preparedness is reported on the basis of self-assessment and may be influenced by a multitude of factors, including e.g. political factors. The Ebola epidemic has shown that the WHO does not have the capacity to enforce the existing requirements. Despite Member States accepted the 2005 IHR and the deadlines for improving their systems, they are not taking sufficient action [15].

The 2005 IHR also defines the WHO DirectorGeneral's duty to declare a Public Health Emergency of International Concern (PHEIC). However, as the influenza pandemic has shown, the announcement of such a state has many consequences not only in relation to the actions taken by the medical sector, but also in relation to the possibility / necessity of implementing measures that may have a huge impact, for instance, on the political and economic aspects of a given region $[15,17]$. During the course Ebola epidemic, the WHO announced the PHEIC only in August 2014. According to the experts, this decision was taken too late, and as it was the solely responsibility of the WHO Director-General, it was not possible to consult more widely on it.

\section{DISCUSSION AND CONCLUSION}

The above analysis only includes selected examples of preventive measures that can be taken during an outbreak of infectious diseases. Analyzing the conclusions drawn from the preparation and response to the influenza pandemic and comparing them with the actions taken during the Ebola epidemic, we can certainly conclude that it was not fully drawn from the lessons that influenza, SARS or MERS gave us $[9,16]$. Many countermeasures were taken hastily, sometimes at a higher loss than in the absence of action in a given area. The absolute lack of long-term measures and clear procedures to prepare health personnel for an epidemic, or the lack of adequate medical infrastructure and personal protective equipment, was very evident. It should be stressed that all these elements of preparation were described in the 2005 IHR as basic requirements for WHO member countries. Unfortunately, as shown by the epidemic, there have been insufficient mechanisms to be used for assessment and verification of the state of preparation of countries for this threat. These problems concerned not only West African countries, but also developed countries in Europe and America. Many of the problems described in the context of the actions presented on the example of African countries are unfortunately descriptions of the weaknesses of many other national systems as well [17].

It is worth noting that during both the influenza pandemic and the Ebola viral disease epidemic, a very similar range of action was taken into account. These included a broad response from the medical sector, including the preparation of hospitals and other care facilities, the health protection of health care personnel, the surveillance of infectious diseases, and the use of medicines and vaccines, among others. A wide group also consisted of so-called non-pharmaceutical measures including, for example, the possibility of isolation and quarantine, school closures, travel restrictions or the use of personal protective equipment in the entire population. Communication, both between response services and with the public, was an important part of the preparations in each case.

All these measures have already been used in the past and conclusions as to their effectiveness or lack thereof were based on the course of previous epidemics. In-depth analyses in this respect have been carried out in connection with pandemic influenza preparations, during which the validity of the implementation of specific strategies has been discussed over the years. Of course, in addition to the epidemiological situation, the analyses also took into account climatic, geopolitical and cultural differences.

Unfortunately, as the Ebola epidemic has shown, the solutions developed in many cases have not been reflected in the response to the threat $[16,17]$. The reasons for this state of affairs can be seen, among others in limited communication between experts dealing with various infectious diseases, as well as the multiplicity of existing plans, procedures, strategies and lack of coordination of activities. Sometimes, as in the case of previous outbreaks, panic and political correctness have proved to be more important advisors than scientific reports and previous experiences.

Errors were also due to the lack of a single coherent strategy which would set out the main objectives 
for action during infectious disease outbreaks. It is extremely important to draw up such a document beforehand, and not during an epidemic. This will make it possible to make appropriate arrangements between the various services in advance, to practice the assumptions made and to avoid pressure from politicians, the media and pseudo-experts alike. Such a strategy, which applies to Poland as well, should contain the key directions of the country's response and long-term planning activities in various areas, including, above all, precise assumptions concerning the training of personnel in the field of personal protection and response during an epidemic of infectious diseases. It should also specify to what extent training should be provided to all staff of the medical sector, and to what extent only to those selected, designated to respond in situations of similar threats, e.g. adhesion to Poland of a dangerous infectious disease [10]. The strategy should provide for a long-term program of such training, as a continuous process, combined with exercises and aptitude tests. The Ebola virus epidemic has shown how important it is to properly train and secure staff - this should be the basis of any national preparation strategy.

It is necessary to agree precisely upon the assumptions concerning the response during an epidemic of infectious diseases, e.g. in the scope of activities of the civil aviation sector, the rules of school closures, or the introduction of isolation and quarantine. All of this goes well beyond the remit of institutions responsible for public health. That is why it is so important to make others aware of their role, as well as their responsibility in this type of crisis.

Establishing general rules of response, together with a clear justification, should be the basis for the preparation and response of each country. As was the case during the course of preparation of the pandemic influenza plans, these strategies should be discussed at international level, at the very least by neighboring countries. Preparations for the influenza pandemic have shown that such consultations are possible and that, even if national assumptions differ, common solutions and a possible compromise on discrepancies is achievable.

In order for international action to be carried out properly, it is necessary to strengthen the role of the WHO, the weaknesses of which were evident during both the influenza pandemic and the Ebola viral disease epidemic [16]. The role of this organization is enormous, but it should be able to enforce the accurate, previously accepted assumption of the IHR 2005 better. The current level of implementation of this document is far from sufficient.

At the European Union level, we should return to the assumptions of "Generic preparedness" described, among others, in the Communication from the Commission to the Council, the European Parliament, the European Economic and Social Committee and the Committee of the Regions on strengthening coordination on generic preparedness planning for public health emergencies at EU level (November 2005), which were discussed earlier, however, due to the influenza pandemic, they have been pushed aside, or those described later in "Strategy for Generic Preparedness Planning Technical guidance on generic preparedness planning for public health emergencies" (April 2011) and Decision No 1082/2013/EU of the European Parliament and of the Council of 22 October 2013 on serious crossborder threats to health. These documents, updated in accordance with new experience, could form the basis for further work.

Properly defined cooperation with the media and education of the public should also be an important element of the strategy. As shown in previous analyses, these two elements have a great impact on the correct response during crises and are now a key element of the crisis management system in the event of an epidemic of infectious diseases. It should be stressed that only long-term educational and awareness-raising action can bring results in this area.

It would seem that the above mentioned conclusions are a rather long list of difficult to implement requirements, as well as too idealistic an approach to planning. However, in the authors' opinion, this is one of the ways to improve the response, simultaneously taking into account such important elements as the safety of medical personnel or the involvement of the public in the cooperation. This list does not cover all areas of preparation. It should be developed in the light of the level of preparation achieved.

According to the authors, the system cannot be built or even improved during or just before the epidemic. Such actions need be done well before the crisis, so that changes and modifications, sometimes very controversial, can be made without pressure and can be tested. Raising public awareness of the risks, opportunities to contribute to the preparation and, at the same time, the costs of not participating in the preparation process is crucial as well. All of this requires a long-term educational effort, not ad hoc action.

The epidemic of viral disease Ebola was not a surprise. It was a crisis that we should have expected. The approach that 'it is not our crisis, it is not our threat' failed. Changing this mindset in regard to both naturally occurring epidemics and the possibility of a bioterrorist attack should be a first step in further preparation. 


\section{AUTHORS' DECLARATION:}

Study Design: Anna Świątecka, Wojciech Dębiński; Data Collection: Anna Świątecka, Wojciech Dębiński; Manuscript Preparation: Anna Świątecka, Wojciech Dębiński; Funds Collection: Anna Świątecka, Wojciech Dębiński. The Authors declare that there is no conflict of interest.

\section{REFERENCES}

1. Curran KG, Gibson JJ, et al. Cluster of Ebola Virus Disease Linked to a Single Funeral - Moyamba District, Sierra Leone, 2014. MMWR Morb Mortal Wkly Rep. 2016; 65:202-205.

2. Dembek Z. The Last Word CBNW Chemical, Biological \& Nuclear Warfare. 2017; 63-66.

3. Diseases TLI. Ebola in west Africa. The Lancet Infectious Diseases. 2014; 14:779.

4. Diseases TLI. Rationality and coordination for Ebola outbreak in west Africa. The Lancet Infectious Diseases. 2014; $14: 1163$.

5. Ebola event management at points of entry Interim guidance WHO September 2014

6. Exit screening at airports, ports and land crossings: Interim guidance for Ebola virus disease WHO November 2014.

7. Farmer P. The largest ever epidemic of Ebola. Reproductive Health Matters. 2014; 22:157-162.

8. Farmer P. The Caregivers' Disease, London Review of Books, May 2015.

9. Gates B. Preparing for the Next Epidemic: A First Step www.gatesnotes.com , January 2017.

10. GO pre-deployment training: participant handbook WHO, May 2015.

11. Gostin L. The International Health Regulations and beyond. The Lancet Infectious Diseases. 2004; 4:606-607.

12. Gostin LO, Sridhar D, Hougendobler D. The normative authority of the World Health Organization. Public Health. 2015; 129:854-863.

13. Gut W, Pancer K. Filowirusy - wybrane problemy na tle epidemii wywołanej wirusem Ebola Przegląd Epidemiologiczny. 2015; 69(1):125-130 .

14. How to conduct safe and dignified burial of a patient who has died from suspected or confirmed Ebola virus disease Ross AG, Crowe SM, Tyndall MW. Planning for the Next Global Pandemic International Journal of Infectious Diseases. 2015; 38:89-94.

15. Technical note for Ebola preparedness planning for entry screening at airports, ports and land crossings WHO, December 2014.

16. Technical report Infection prevention and control measures for Ebola virus disease. Entry and exit screening measures ECDC, October 2014.

17. WHO Ebola Virus Fact Sheet. http://www.who.int/mediacentre/factsheets/fs103/en/

18. Wojewódzki Plan Działania na Wypadek Wystąpienia Epidemii na Terenie Województwa Mazowieckiego.

19. Wojewódzki Plan Działania na Wypadek Wystąpienia Epidemii na Terenie Województwa Małopolskiego.

\section{ACKNOWLEDGEMENTS}

The views, opinions, and findings contained in this article are our own and should not be construed as an official Polish Air Force position, policy, or decision, unless so designated by other official documentation.

Cite this article as: Świątecka A, Dębińsk W. Planning Actions in The Event of an Epidemic of Infectious Diseases . Pol J Aviat Med Bioeng Psychol 2017; 23(2): 28-36. DOI: 10.13174/pjambp.16.07.2018.04 